\title{
Correction to: An Allometric Scaling for the Number of Representative Nodes in Social Networks
}

\author{
Liang Zhao and Tianyi Peng
}

\section{Correction to:}

Chapter 4 in: N. Masuda et al. (eds.), Proceedings of NetSci-X 2020: Sixth International

Winter School and Conference on Network Science, Springer Proceedings in Complexity, https://doi.org/10.1007/978-3-030-38965-9_4

The original version of this chapter was inadvertently published with middle initial of the second author "Tianyi Y. Peng". The middle initial has been removed as per author's request and updated as "Tianyi Peng".

The updated online version of this chapter can be found at https://doi.org/10.1007/978-3-030-38965-9_4 